\title{
Consolidation treatment for high risk solid tumors in children with myeloablative chemotherapy and autologous hematopoietic progenitor stem cell transplantation
}

\author{
Alberto Olaya Vargas \\ Roberto Rivera Luna \\ Martin Perez Garcia \\ Rocio Cárdenas Cardos \\ Liliana Velasco Hidalgo \\ Doris LordMéndez Jácome \\ Mariana Campos Gutiérrez
}

National Institute of Pediatrics - INP, Mexico City, AC, Mexico
Conflict-of-interest disclosure:

The authors declare no competing financial interest

Submitted: 11/21/2012

Accepted: 7/20/2013

\author{
Corresponding author: \\ Alberto Olaya Vargas \\ National Institute of Pediatrics - INP \\ Stem Cell Hematopoietic Transplant Program \\ Insurgentes Sur 3700-C \\ 04530 Mexico City, AC, Mexico \\ olayavargasalberto@gmail.com
}

Background: In childhood cancer, consolidation treatment with chemotherapy followed by autologous hematopoietic progenitor stem cell transplantation is currently an accepted treatment modality in patients with high-risk solid tumors or in patients who have relapsed after conventional treatment.

Objectives: The objective of this study was to describe the results of transplantation of a group of children who had high-risk solid tumors or relapsed after conventional chemotherapy regimens.

Methods: A retrospective analysis was conducted from January 1998 to October 2004 of all children with pathologic diagnoses of high-risk solid tumors or children that had previously relapsed after conventional chemotherapy and that were subsequently submitted to autologous hematopoietic progenitor stem cell transplantation. The analysis included overall survival rates, event-free survival rates, mortality rates and chemotherapy complications.

Results: Nineteen patients were submitted to this approach. The age range was from 27 to 196 months with a median age of 52 months. The overall survival rate at 100 days was observed in $79 \%$, the three-year event-free survival rate was $63 \%$. The mortality rate secondary to the myeloablative chemotherapy regimen was $21 \%$ ( $n$ =4). Only three patients (15.8\%) relapsed with tumor progression after transplant.

Conclusion: Autologous hematopoietic progenitor stem cell transplantation is still a successful procedure in patients with solid tumors refractory to conventional chemotherapy.

Keywords: Hematopoietic stem cell transplantation; Neoplasms; Child

\section{Introduction}

Recently, disease-free survival (DFS) for children with solid tumors has improved considerably; more than $70 \%$ of children achieve 5-year tumor-free survival. However, there is a group of patients who have some clinical and biological characteristics with poor prognostic factors at diagnosis.

Unfavorable factors are associated with a high failure rate to traditional treatment regimens including chemotherapy, surgery and radiotherapy. Therefore, children with solid tumors and adverse risk factors require new therapeutic strategies ${ }^{(1)}$.

Preclinical studies and clinical correlations of the effect of alkylating agents have demonstrated that there is a linear-logarithmic relationship between the chemotherapy dose and cytotoxicity. Therefore, increases in chemotherapy of 3 to 10 times denote multiplelogarithmic increases in the destruction of malignant cells. However, the main limit of this principle is the extended myelotoxicity which puts the patient's life at risk ${ }^{(2-6)}$.

The reconstitution of the hematopoietic system after myeloablative doses of chemotherapy and/or total body irradiation (TBI) can induce severe or even fatal complications if the patient is not rescued with autologous CD34 hematopoietic progenitor cells obtained either from bone marrow or peripheral blood. This approach has been one of the most highly successful strategies to limit secondary myelotoxicity ${ }^{(3,7)}$.

Many investigators have demonstrated the importance of using myeloablative doses with different chemotherapeutic regimens including hematologic support with hematopoietic stem cell transplantation. This approach, widely used as consolidation therapy in high-risk solid tumor pediatric patients, has proved to be an excellent complement to conventional multidisciplinary approaches including surgery and chemotherapy ${ }^{(4,8)}$. However, there are many questions regarding the best combination of myeloablative chemotherapy for these types of tumors, how to eliminate TBI from myeloablative regimens without any significant change in response rates, as well as which of these strategies is the best to avoid further relapse in this group of children.

The aim of the current study was to evaluate the efficacy and safety of a myeloablative chemotherapy program without TBI using melphalan, cyclophosphamide and etoposide followed by consolidation-rescue with autologous hematopoietic progenitor stem cell transplantation (AHPSCT) as treatment for high-risk solid tumors in children. All these drugs, with demonstrated efficacy, are available in Mexico ${ }^{(6)}$. 


\section{Methods}

A phase II clinical protocol was carried out according to the best clinical practice guidelines. The protocol was approved by the Ethics Committee of the institution, guaranteed by the Comisión Federal para la Protección contra Riesgos Sanitarios (COFEPRIS). Inclusion criteria were an age of under 18 years old with high-risk solid tumors and advanced tumor stage from January 1998 to October 2004 and followed for up to 121 months after transplantation. All patients were registered in our institution. Parents of patients signed an informed consent form in accordance with the Helsinki Declaration as revised in 2008. Within these criteria, this population needed to have a disease-free life survival expectancy of less than $25 \%$ with conventional therapy at the time of diagnosis or advance disease after the first relapse.

All patients went through conventional treatment protocols, including surgery, radiotherapy and chemotherapy, prior to being considered eligible for the AHPSCT procedure. Patients who demonstrated a tumor response greater than $90 \%$ in diameter determined by image studies before entering the transplantation program were included. Children with partial response $(<90 \%)$ or relapse were excluded. All patients included in the study were fully evaluated before entering the AHPSCT program. Those with any evidence of organic dysfunction were excluded from this program.

\section{Cryopreservation of progenitor cells}

The hematopoietic progenitor cells were obtained from bone marrow in the operating room under general anesthesia through multiple punctures of both posterior-superior iliac crests or peripheral blood through apheresis ${ }^{(9)}$ using a Baxter cell separator model CS300 through a double lumen central catheter. Mobilization of progenitor cells was obtained using colony stimulating granulocyte factor at $10 \mathrm{mcg} / \mathrm{kg} /$ day for 5 days, prior to the collection ${ }^{(5)}$. Bone marrow or peripheral blood stem cells were preserved by cryopreservation as published elsewhere ${ }^{(10)}$ until they were re-infused intravenously. In both cases the collection of the progenitors was carried out to obtain from 3.5 to $4.5 \times 10^{8}$ mononuclear cells per kilogram of patient's weight. Through flow cytology the cell dose was established to guarantee a graft in a range of 3-5 x $10^{6} \mathrm{CD} 34^{+}$cells $/ \mathrm{kg}^{(11,12)}$.

Cryopreservation was carried out through a programmable cryopreservation unit that allowed a gradual temperature decrease of $-1{ }^{\circ} \mathrm{C} / \mathrm{min}$ over 90 minutes; $10 \%$ dimethyl sulfoxide (DMSO) was used as a cryoprotective agent. Thus, the progenitor cells were stored in liquid nitrogen at $-190^{\circ} \mathrm{C}^{(10)}$ until the day of the infusion. An in vitro purge using methylprednisolone and etoposide was carried out for patients who presented bone marrow tumor infiltration using the doses and methodology published elsewhere ${ }^{(13)}$. Subsequent $0.4 \%$ trypan blue exclusion test was performed to assess cell viability.

\section{Myeloablation regimen}

After the hematopoietic progenitor cells were obtained, children were initiated with a hydration program at $3000 \mathrm{~mL} /$ $\mathrm{m}^{2} /$ day from Day -10 to Day 0 . The myeloablation program consisted of oral melphalan $200 \mathrm{mg} / \mathrm{m}^{2}$ split over four days commencing from Day -9 to Day -6 , intravenous (IV) cyclophosphamide at $120 \mathrm{mg} / \mathrm{kg}$ split over two days (Day -5 and Day -4) and IV etoposide at $1200 \mathrm{mg} / \mathrm{m}^{2}$ was administered as a 24-hour infusion on Day -3. On Days - 2 and -1 the patients received only intravenous hydration.

\section{Infusion of hematopoietic progenitors}

The infusion was carried out on Day 0. The bags of thawed units were transported directly to the transplant unit at a temperature of $4^{\circ} \mathrm{C}$. They were infused in a closed system, through a central line over an average time of ten minutes. All the patients were treated with a single IV dose of furosemide (1 $\mathrm{mg} / \mathrm{kg}$ ), a single IV dose of ondansetron $\left(5 \mathrm{mg} / \mathrm{m}^{2}\right)$ and a single IV dose of methylprednisolone $\left(2 \mathrm{mg} / \mathrm{m}^{2}\right)$ prior to the infusions.

\section{Prophylactic therapy and hematopoietic support}

All children had intravenous prophylactic treatment with fluconazole $(10 \mathrm{mg} / \mathrm{kg} /$ day/dose) and acyclovir $(10 \mathrm{mg} / \mathrm{kg} / \mathrm{day} /$ dose). Immunoglobulin was not routinely used in these patients because the cost is very high; it was preferred to monitor immunoglobulin levels with administration only to those with low levels during or after transplant. Granulocyte colony stimulating factor was administered intravenously at $10 \mathrm{mcg} / \mathrm{kg}$ every 24 hours from Day +3 . These medications were administered when the neutrophil count was under $0.5 \times 10^{9}$ cells $/ \mathrm{L}$ and maintained until the count was above $1.0 \times 10^{9}$ cells/L. At that time, children had their treatment changed to oral medications, which included fluconazole $(10 \mathrm{mg} / \mathrm{kg} /$ day $)$ and prophylaxis with trimethoprimsulfamethoxazole $(10 \mathrm{mg} / \mathrm{kg} /$ day $)$ three times per week for 60 days .

Children were transfused packed red blood cells at $10-20 \mathrm{~mL} /$ $\mathrm{kg}$ when hemoglobin levels were below $8.0 \mathrm{~g} / \mathrm{dL}$; if the platelet count was below $20 \times 10^{3} / \mu \mathrm{L}$, apheresis platelet transfusion was administered. All blood transfusion products were previously irradiated.

\section{Response assessment}

A transplant graft was considered successful when the neutrophil count increased by more than $0.5 \times 10^{9}$ cells/L and the reticulocyte count by more than $2 \%$ within the first 30 days after transplant.

Data was gathered on forms especially designed for the study. The STATA package version 11 was used for statistical analysis. Data on the overall survival (OS) and event-free survival (EFS) were analyzed as was the toxicity with central trends, spread, frequencies and means. An actuarial Kaplan Meier method was used to determinate the OS and EFS considering the period between the AHPSCT and the time of death, relapse or the last visit to the center.

Similarly, the parameters of efficiency were defined as EFS evaluated at 118 to 121 months. Safety parameters were defined as an OS at Day 100 post-transplant adjusted according to the hematologic and non-hematologic toxicity criteria established by the World Health Organization (WHO). 


\section{Results}

A total of 19 consecutive patients (ten male $-52.6 \%$ and nine female $-47.4 \%$ ) were enrolled in this study. The ages ranged from 27 to 192 months with a median age of 52 months (Table 1). The commonest diagnosis was neuroblastoma in nine cases $(47.4 \%)$ of which $89 \%$ were stage IV and $11 \%$ stage III according to the International Neuroblastoma Staging System; three patients (33.3\%) presented infiltration of the bone marrow at the time of diagnosis.

The Ewing sarcoma family of tumors (ES) was the second most common diagnosis in $26.3 \%$ of the cases $(n=5)$; all had metastatic disease in the bone at the time of diagnosis. Similarly, two patients (40\%) presented infiltration of the bone marrow and one patient $(20 \%)$ had metastasis to the liver. Two patients had Wilms tumors $(10.5 \%)$ after the first relapse. Three patients were found to have germinal tumors-endodermal sinus tumor $(15.7 \%)$ that, similar to the other patients with Wilms tumors, achieved a second complete remission.

The bone marrow was used as the source of hematopoietic progenitor cells in six patients $(31.6 \%)$ and peripheral blood in 13 $(68.4 \%)$. On average, two aphaereses were required to obtain an adequate dose of mononuclear cells.

The median dose of mononuclear cells was $4 \times 10^{8} / \mathrm{kg}$ of the recipients weight with an interquartile range (IQR) of 0.6 (Range: $3.5-12.3 \times 10^{8} / \mathrm{kg}$ ). The median quantity of CD $34^{+}$cells was 3.16 x $10^{6}$ (IQR 1.5) (Range: 1.2-6.4 x 106/ kg). In vitro purges with methylprednisolone and etoposide were used in only three cases. Viability using the trypan blue exclusion test was higher than $90 \%$. The median time to neutrophil engraftment was 22 days (Range: 19-
26 days) for patients transplanted with bone marrow while for those transplanted with peripheral blood, the median time to neutrophil engraftment was 14 days (Range: 10-19 days). There was a statistically significant difference between the groups ( $\mathrm{p}$-value = 0.002). Engraftment was not attained in only one case (5.3\%).

The median time to platelet engraftment was 45 days (Range: 32-68 days) for patients transplanted with bone marrow while for those transplanted with peripheral blood the median time was 36 days (Range: 29-58 days). The median time of hospital stay within the transplant unit was 30 days (Range: 22-42 days).

The OS at 100 days was $79 \%$ and EFS was $63 \%$ in a 3 -year follow-up period (Figure 1). Currently 11 patients are alive and without evidence of tumor activity. Eight patients died; for five patients (26\%) death was associated to the myeloablative chemotherapy regimen with the secondary cause being septic shock. Only three patients $(15 \%)$ relapsed with tumor progression after transplant.

The most common toxicity was neutropenia with all 19 patients $(100 \%)$ presenting grade IV toxicity (WHO criteria). On average toxicity was present on Day +3 (Range: Day -3 to Day +5 ). As a whole, patients required an average of 5.8 transfusions of packed red blood cells (Range: 2-19). Platelets by aphaeresis transfusions were administered with a median of 11.6. Granulocyte stimulating factor was given for an average of 19 days (Range: 11-32 days; median: 24).

The second cause of toxicity was gastrointestinal with 12 patients presenting with mucositis $(63 \%)$ : two patients $(16.7 \%)$ level IV, four children (33.3\%) level III and six patients $(50 \%)$ level II. Neutropenic colitis was presented by seven patients $(36.8 \%)$ all of whom required parenteral nutrition.

Table 1 - Pediatric patients submitted to autologous hematopoietic progenitor stem cell transplantation (AHPSCT)

\begin{tabular}{|c|c|c|c|c|c|c|c|c|c|}
\hline $\begin{array}{l}\text { Patient } \\
\text { number }\end{array}$ & Diagnosis & Gender & Stage & $\begin{array}{c}\text { Age } \\
\text { (months) }\end{array}$ & $\begin{array}{c}\text { Status of } \\
\text { remission } \\
\text { prior to } \\
\text { AHPSCT }\end{array}$ & $\begin{array}{c}\text { Source } \\
\text { of } \\
\text { Stem } \\
\text { cells }\end{array}$ & $\begin{array}{l}\text { Current } \\
\text { status }\end{array}$ & $\begin{array}{l}\text { Last } \\
\text { visit }\end{array}$ & $\begin{array}{c}\text { Cause } \\
\text { of dead }\end{array}$ \\
\hline 1 & Neuroblastoma & Male & IV & 48 & $2^{\text {nd }}$ & $\mathrm{BM}$ & Alive & $3 / 2008$ & \\
\hline 2 & Ewing sarcoma & Female & $\begin{array}{l}\text { Metastasis to Bone, bone } \\
\text { marrow }\end{array}$ & 192 & $1^{\text {st }}$ & $\mathrm{BM}$ & Dead & $10 / 1998$ & Sepsis \\
\hline 3 & Neuroblastoma & Female & IV & 24 & $1^{\text {st }}$ & $\mathrm{PB}$ & Alive & $6 / 2005$ & \\
\hline 4 & Ewing sarcoma & Male & $\begin{array}{l}\text { Metastasis to Bone, bone } \\
\text { marrow }\end{array}$ & 108 & $1^{\text {st }}$ & $\mathrm{BM}$ & Dead & $9 / 1999$ & Sepsis \\
\hline 5 & Neuroblastoma & Male & IV & 52 & $1^{\text {st }}$ & $\mathrm{BM}$ & Alive & $3 / 2011$ & \\
\hline 6 & Germ cell tumor & Female & Metastasis to lung & 132 & $2^{\text {nd }}$ & $\mathrm{BM}$ & Dead & $1 / 2001$ & Relapsed \\
\hline 7 & Neuroblastoma & Female & IV & 24 & $1^{\text {st }}$ & PB & Alive & $6 / 2006$ & \\
\hline 8 & Germ cell tumor & Male & Metastasis to mediastinum & 96 & $1^{\text {st }}$ & PB & Alive & $1 / 2004$ & \\
\hline 9 & Neuroblastoma & Female & IV & 36 & $1^{\text {st }}$ & $\mathrm{BM}$ & Alive & $11 / 2006$ & \\
\hline 10 & Wilms tumor & Female & IV & 52 & $2^{\text {nd }}$ & $\mathrm{PB}$ & Alive & $8 / 2004$ & \\
\hline 11 & Neuroblastoma & Male & IV & 32 & $1^{\text {st }}$ & $\mathrm{PB}$ & Dead & $5 / 2001$ & Sepsis \\
\hline 12 & Neuroblastoma & Male & IV & 48 & $1^{\text {st }}$ & $\mathrm{PB}$ & Alive & $3 / 2006$ & \\
\hline 13 & Wilms tumor & Male & IV & 108 & $2^{\text {nd }}$ & $\mathrm{PB}$ & Alive & $11 / 2006$ & \\
\hline 14 & Neuroblastoma & Male & IV & 54 & $1^{\text {st }}$ & $\mathrm{PB}$ & Dead & $9 / 2004$ & Relapsed \\
\hline 15 & Ewing sarcoma & Female & $\begin{array}{l}\text { Metastasis to bone, bone } \\
\text { marrow, liver }\end{array}$ & 192 & $1^{\text {st }}$ & $\mathrm{PB}$ & Dead & $3 / 2004$ & Relapsed \\
\hline 16 & Germ cell tumor & Male & IV & 84 & $1^{\text {st }}$ & $\mathrm{PB}$ & Alive & $3 / 2010$ & \\
\hline 17 & Ewing sarcoma & Female & Metastasis to bone & 48 & $1^{\text {st }}$ & $\mathrm{PB}$ & Dead & $4 / 2004$ & Sepsis \\
\hline 18 & Neuroblastoma & Female & III & 32 & $1^{\mathrm{st}}$ & $\mathrm{PB}$ & Alive & $2 / 2011$ & \\
\hline 19 & Ewing sarcoma & Male & Metastasis to lung and bone & 168 & $1^{\text {st }}$ & $\mathrm{PB}$ & Dead & $11 / 2004$ & Sepsis \\
\hline
\end{tabular}

BM: bone marrow; PB: peripheral blood 
Infectious complications were identified in 11 patients $(57.9 \%)$. Four patients $(36.3 \%)$ had bacteriologically isolated septicemia, three patients $(27.3 \%)$ had pneumonia, two $(18.2 \%)$ had rectal abscess and the other two patients had skin infections. The isolated germs were enterobacteria in $45.5 \%(\mathrm{n}=5)$ of the cases, Staphylococcus epidermidis in $27.3 \%(\mathrm{n}=3)$ and Candida albicans in $27.3 \%(\mathrm{n}=$ 3 ). Hepatic toxicity was presented by four patients (21\%); all cases were identified by liver function tests. Six patients $(31.6 \%)$ required intensive care, four of whom died as previously mentioned. None of the patients had veno-occlusive disease.

We observed that the type of tumor histology was important because survival of patients with ES was $20 \%$ in a follow-up of between three and 18 months. However, the EFS in the same period was $0 \%$ in comparison to those with neuroblastoma, where the OS was $88.8 \%(\mathrm{p}$-value $=0.035)$ in a follow-up of from three to 89 months and the EFS was $77.8 \%$ (p-value $=0.01$ ). The median survival of all patients was between 118-121 months (Figure $1 \& 2$ ).

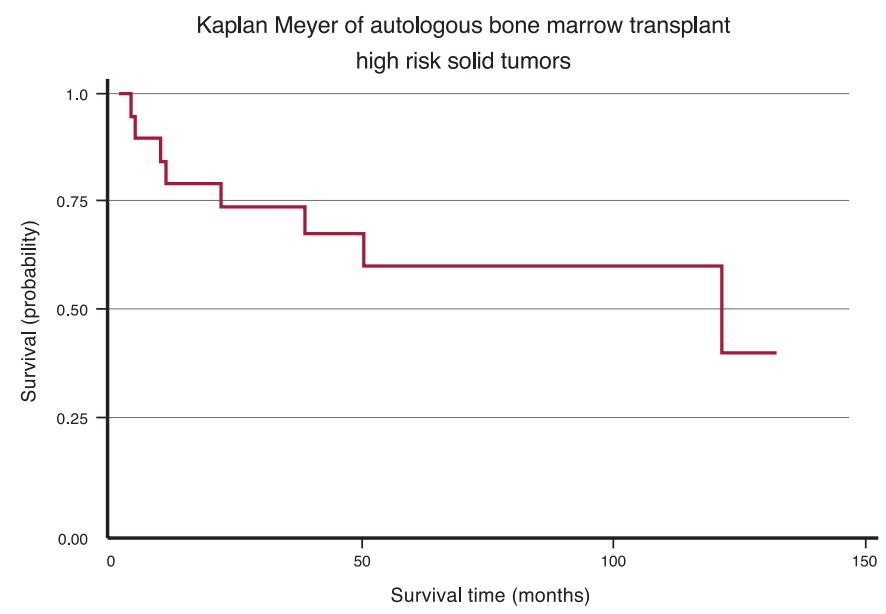

Figure 1 - Event-free survival of 19 pediatric patients with high-risk solid tumors conditioned with melphalan, cyclophosphamide and etoposide and autologous hematopoietic progenitor stem cell transplantation

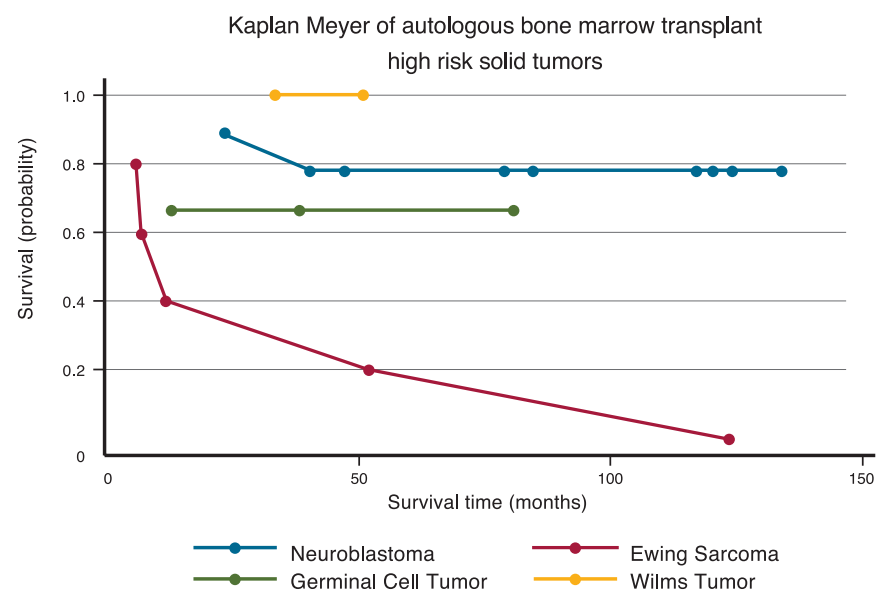

Figure 2 - Event-free survival by tumor type in 19 pediatric patients conditioned with melphalan, cyclophosphamide and etoposide and autologous hematopoietic progenitor stem cell transplantation
Another important factor was the time at onset of severe bone marrow aplasia. The patients were divided into two groups in respect to this variable. Group 1, patients presenting severe aplasia before Day $0(\mathrm{n}=5)$ and Group 2, patients presenting aplasia after Day $0(n=14)$. The OS at Day 100 for Group 1 was $20 \%$ while for Group 2 it was $100 \%$ (p-value $=0.02$ ).

The presence of bacterial infections had an influence on the outcome with a survival of $20 \%$ at Day 100 compared with $100 \%$ for the patients who did not have bacterial infections.

The synergy between early severe myelotoxicity-bone marrow aplasia and infectious complications were the most unfavorable factors and documented in four patients that died.

\section{Discussion}

Clinical evidence has demonstrated the effectiveness of increasing chemotherapy doses to enhance the destruction of tumor cells. This is the most solid basis for myeloablative chemotherapy in AHPSCT as consolidation treatment for highrisk solid tumors. It can be achieved by alkylating agents alone or in combination with some other agents depending upon the type of tumor ${ }^{(14,15)}$.

In most cases the benefit has been complemented with the use of $\mathrm{TBI}^{(16)}$. However the short and long-term deleterious effects of radiation in children increase the morbidity and decrease, in many cases, the quality of life without an easily identifiable therapeutic benefit ${ }^{(17)}$.

In a previous work by our group of 15 consecutive children with advanced cancer submitted to three different myeloablative chemotherapy regimens and AHPSCT, the OS was $40 \%$ and the mean DFS was 19 months ${ }^{(6)}$. However the current study shows that single chemotherapy regimens can give more standardized results. Morbidity and a strict patient selection probably would offer better results. The present investigation evaluated the results of a single chemotherapy regimen based on melphalan, cyclophosphamide and etoposide without TBI. The EFS for the entire group was $63 \%$ in a three-year follow-up. Initially, these results exceeded the life probability for patients, as they had relapsed to first and/or second line conventional chemotherapy regimens.

A conditioning scheme with melphalan, cyclophosphamide and etoposide was selected, because it has proven to be efficient when treating multiple solid tumors in childhood, besides the fact of being accessible and affordable in Mexico.

The results obtained in this research are similar to those obtained by other groups. In 1998 Ozkaynak $^{(18)}$ reported a similar experience in 27 pediatric patients with high-risk solid tumors using a combination of alkylating agents (cyclophosphamide, carboplatin, melphalan and etoposide) and AHPSCT. DFS at 3 years was $60 \%$, patients presented engraftment by Day +12.5 and presented a $16 \%$ transplant-related mortality rate. All deaths were caused by secondary sepsis due to infections by candida. After surgery, patients were examined daily while in the hospital and then at one and six weeks after discharge. Follow-up evaluations were then conducted at 3- to 6-month intervals for the first year and thereafter yearly for the remainder of the patient's life.

Kletzel $^{(19)}$ demonstrated the usefulness of myeloablative doses of chemotherapy followed by AHPSCT in a phase I/ 
II study of patients with high-risk neuroblastoma. They used the combination of thiotepa (300 $\mathrm{mg} / \mathrm{m}^{2} /$ day) for three days followed by cyclophosphamide $\left(1500 \mathrm{mg} / \mathrm{m}^{2} /\right.$ day) for four days. In addition, an in vitro purge of bone marrow was carried out for 16 patients; the bone marrow was not purged for 23 patients. Peripheral blood was used in 13 patients with engraftment by Day 19 in patients with purged bone marrow and by Day 17.5 in patients with non-purged bone marrow and by Day 13 in patients that were given peripheral blood. Twenty-nine out of 51 patients that were included in the study presented progressive disease in a follow-up of 1140 days. There are multiple studies that have demonstrated the usefulness of melphalan in the myeloablation regimen $^{(20,21)}$ for neuroblastoma; however, most of them include TBI. In these studies the OS did not exceed $40 \%$. This was due to the elevated mortality rate secondary to TBI. Even so, these studies outline the usefulness of melphalan to treat neuroblastoma. This observation is substantiated by the current study, in which, analyzing the group of patients with neuroblastoma separately, the OS was $88.1 \%$ and the EFS was $77.8 \%$.

The use of high dose chemotherapy followed by AHPSCT in patients with high-risk Wilms tumor and/or after relapse has been established as an efficient therapy as reported by Campbell et al. ${ }^{(22)}$. These authors treated 13 patients after the first relapse. All patients were given different ablative regimens. The EFS was $60 \%$ and there was no transplant-related mortality.

The current study included patients with germ cell tumors after the first relapse. It is important to consider that the experience with high-dose chemotherapy and autologous stem cell transplant in children is still limited. In adult patients the experience is broader. Recently, a study of adult patients showed that half of the patients submitted to this procedure had a favorable outcome ${ }^{(23)}$.

We consider the results with ES in this study are not comparable with those obtained by other $\operatorname{groups}^{(24)}$. The combination of chemotherapeutic agents used in our study did not have an impact on the EFS. Therefore, we must consider the use of a new regimen of myeloablation chemotherapy. Currently some groups have obtained promising results in ES with an OS of $53 \%$ to $86 \%{ }^{(25)}$. In these studies a combination of carboplatin, ifosfamide and etoposide was used ${ }^{(26)}$. Other childhood solid tumors have been evaluated including osteosarcoma ${ }^{(27)}$, medulloblastoma $^{(28)}$ and malignant astrocytoma ${ }^{(29)}$.

The rate of infectious complications in our series, as well as mortality associated with the transplant protocol is higher than what has been reported in international literature. The rate of infectious complications in first transplant patients in our unit has decreased due to an increase in the experience of the group with this type of patients. This has enabled us to continue the autologous transplant program for solid tumors in an outpatient program with favorable results. AHPSCT can be harvested from bone marrow progenitor cells although peripheral blood is a more viable option especially in pediatric patients. However, cord blood is another realistic source given the potential contamination with tumor cells from the same patient and the risk of myelodysplastic syndrome post-transplant.

There is no question that this therapeutic approach is harmless not only in the acute phase of treatment but in the medium and long term follow up especially for children that received TBI as part of their treatment $\operatorname{protocol}^{(30,31)}$.

\section{Conclusion}

AHPSCT is still a successful procedure in patients with solid tumors refractory to conventional chemotherapy.

Novel conditioning regimens, primarily reduced intensity and non-myeloablative regimens, allow patients with significant co-morbidities to undergo transplantation with reduced morbidity and mortality. Combinations of immune-modulatory cytokines and monoclonal antibodies with autologous transplantation are among the advances being explored in contemporary hematopoietic stem cell transplantation. We should continue selecting children with advanced stage high-risk solid tumors, who may benefit from this treatment modality.

The challenge in the future will be to establish strategies that avoid subsequent relapses after AHPSCT using measures such as immunotherapy or target therapy.

\section{References}

1. Ozkaynak MF, Sahdev I, Gross TG, Levine JE, Cheerva AC, Richards $\mathrm{MK}$, et al. A pilot study of addition of amifostine to melphalan, carboplatin, etoposide, and cyclophosphamide with autologous hematopoietic stem cell transplantation in pediatric solid tumors-A pediatric blood and marrow transplant consortium study. J Pediatr Hematol Oncol. 2008;30(3):204-9.

2. Watanabe H, Watanabe T, Suzuya H, Wakata Y, Kaneko M, Onishi T, et al. Peripheral blood stem cell mobilization by granulocyte colonystimulating factor alone and engraftment kinetics following autologous transplantation in children and adolescents with solid tumor. Bone Marrow Transplant. 2006;37(7):661-8.

3. Shook DR, Triplett BM, Srinivasan A, Hartford C, Dallas MH, Pillai A, et al. Successful allogeneic hematopoietic cell engraftment after a minimal conditioning regimen in children with relapsed or refractory solid tumors. Biol Blood Marrow Transplant. 2013;19(2):291-7.

4. Avramova B, Jordanova M, Michailov G, Konstantinov D, Christosova I, Bobev D. Myeloablative chemotherapy with autologous peripheral blood stem cell transplantation in patients with poor-prognosis solid tumors Bulgarian experience. J BUON. 2006;11(4):433-8.

5. Watanabe H, Watanabe T, Suzuya H, Wakata Y, Kaneko M, Onishi T, et al. Peripheral blood stem cell mobilization by granulocyte colonystimulating factor alone and engraftment kinetics following autologous transplantation in children and adolescents with solid tumor. Bone Marrow Transplant. 2006;37(7):661-8.

6. Rivera-Luna R, Olaya-Vargas A, Meza-Coria C, Cárdenas-Cardos R, LealLeal C, Amador-Zarco J. Is autologous bone marrow transplant (ABMT) and high-dose chemotherapy an approach that can rescue some children with advanced cancer disease? Pediatr Hematol Oncol. 2001;18(7):443-51.

7. Gratwohl A. Activity survey and historical perspective of autologous stem cell transplantation in Europe. Semin Hematol. 2007;44(4):220-6.

8. Ljungman P, Urbano-Ispizua A, Cavazzana-Calvo M, Demirer T, Dini G, Einsele H, Gratwohl A, Madrigal A, Niederwieser D, Passweg J, Rocha V, Saccardi R, Schouten H, Schmitz N, Socie G, Sureda A, Apperley $\mathrm{J}$; European Group for Blood and Marrow. Allogeneic and autologous transplantation for haematological diseases, solid tumours and immune disorders: definitions and current practice in Europe. Bone Marrow Transplant. 2006;37(5):439-49.

9. Alegre A, Díaz MA, Madero L, Granda A, de la Vega A, Villa M, et al. Large-volume leukapheresis for peripheral blood stem cell collection in children: a simplified single-apheresis approach. Bone Marrow Transplant. 1996;17(6):923-7. 
10. Meagher RC, Herzig RH. Techniques of harvesting and cryopreservation of stem cells. Hematol Oncol Clin North Am. 1993;7(3):501-33.

11. Diaz MA, Villa M, Alegre A, Lamana ML, de la Vega A, Granda A, et al. Collection and transplantation of peripheral blood progenitor cells mobilized by G-CSF alone in children with malignancies. Br J Haematol. 1996;94(1):148-54

12. Diaz MA, Alegre A, Villa M, Granda A, de la Vega A, Ramirez M, et al. Pediatric experience with autologous peripheral blood progenitor cell transplantation: influence of CD34+ cell dose in engraftment kinetics. Bone Marrow Transplant. 1996;18(4):699-703.

13. Chao NJ, Blume KG. Bone marrow transplantation. Part II-autologous. West J Med. 1990;152(1):46-51. Comment in: West J Med. 1989;151(6):658-9.

14. Pein F, Michon J, Valteau-Couanet D, Quintana E, Frappaz D, Vannier JP, et al. High-dose melphalan, etoposide, and carboplatin followed by autologous stem-cell rescue in pediatric high-risk recurrent Wilms' tumor: a French Society of Pediatric Oncology study. J Clin Oncol. 1998;16(10):3295-301.

15. Ozkaynak MF, Sahdev I, Gross TG, Levine JE, Cheerva AC, Richards MK, et al. A pilot study of addition of amifostine to melphalan, carboplatin, etoposide, and cyclophosphamide with autologous hematopoietic stem cell transplantation in pediatric solid tumors: a pediatric blood and marrow transplant consortium study. J Pediatr Hematol Oncol. 2008;30(3):204-9.

16. Philip T, Bernard JL, Zucker JM, Pinkerton R, Lutz P, Bordigoni P, et al. High-dose chemoradiotherapy with bone marrow transplantation as consolidation treatment in neuroblastoma: an unselected group of stage IV patients over 1 year of age. J Clin Oncol. 1987;5(2):266-71.

17. Kletzel M, Hewlett B. Pediatric transplantation: results in solid tumors. Curr Hematol Rep. 2005;4(4):260-9.

18. Ozkaynak MF, Matthay K, Cairo M, Harris RE, Feig S, Reynolds CP, et al. Double-alkylator non-total-body irradiation regimen with autologous hematopoietic stem-cell transplantation in pediatric solid tumors. J Clin Oncol. 1998;16(3):937-44.

19. Kletzel M, Abella EM, Sandler ES, Williams LL, Ogden AK, Pollock $\mathrm{BH}$, et al. Thiotepa and cyclophosphamide with stem cell rescue for consolidation therapy for children with high-risk neuroblastoma: a phase I/II study of the Pediatric Blood and Marrow Transplant Consortium. J Pediatr Hematol Oncol. 1998;20(1):49-54.

20. Pritchard J, McElwain TJ, Graham-Pole J. High-dose melphalan with autologous marrow for treatment of advanced neuroblastoma. $\mathrm{Br} \mathrm{J}$ Cancer. 1982;45(1):86-94.

21. Ladenstein R, Pötschger U, Hartman O, Pearson AD, Klingebiel T, Castel V, Yaniv I, Demirer T, Dini G; EBMT Paediatric Working Party. 28 years of high-dose therapy and SCT for neuroblastoma in Europe: lessons from more than 4000 procedures. Bone Marrow Transplant. 2008;41(Suppl 2):S118-27.

22. Campbell AD, Cohn SL, Reynolds M, Seshadri R, Morgan E, Geissler G, et al. Treatment of relapsed Wilms' tumor with high-dose therapy and autologous hematopoietic stem-cell rescue: the experience at Children's Memorial Hospital. J Clin Oncol. 2004;22(14):2885-90.

23. Agarwal R, Dvorak CC, Stockerl-Goldstein KE, Johnston L, Srinivas S. High-dose chemotherapy followed by stem cell rescue for high-risk germ cell tumors: the Stanford experience. Bone Marrow Transplant 2009;43(7):547-52.

24. Burke MJ, Walterhouse DO, Jacobsohn DA, Duerst RE, Kletzel M. Tandem high-dose chemotherapy with autologous peripheral hematopoietic progenitor cell rescue as consolidation therapy for patients with high-risk Ewing family tumors. Pediatr Blood Cancer. 2007;49(2):196-8. Comment in: Pediatr Blood Cancer. 2007;49(2):115-6.

25. Fraser CJ, Weigel BJ, Perentesis JP, Dusenbery KE, DeFor TE, Baker KS, et al. Autologous stem cell transplantation for high-risk Ewing's sarcoma and other pediatric solid tumors. Bone Marrow Transplant. 2006;37(2):175-81.

26. Tanaka K, Matsunobu T, Sakamoto A, Matsuda S, Iwamoto Y. High-dose chemotherapy and autologous peripheral blood stem-cell transfusion after conventional chemotherapy for patients with high-risk Ewing's tumors. J Orthop Sci. 2002;7(4):477-82.

27. Lee JW, Kim H, Kang HJ, Kim HS, Park SH, Kim IO, et al. Clinical characteristics and treatment results of pediatric osteosarcoma: the role of high dose chemotherapy with autologous stem cell transplantation. Cancer Res Treat. 2008;40(4):172-7.

28. Butturini AM, Jacob M, Aguajo J, Vander-Walde NA, Villablanca J, Jubran R, et al. High-dose chemotherapy and autologous hematopoietic progenitor cell rescue in children with recurrent medulloblastoma and supratentorial primitive neuroectodermal tumors: the impact of prior radiotherapy on outcome. Cancer. 2009;115(13):2956-63.

29. Finlay JL, Dhall G, Boyett JM, Dunkel IJ, Gardner SL, Goldman S, Yates AJ, Rosenblum MK, Stanley P, Zimmerman RA, Wallace D, Pollack IF, Packer RJ; Children's Cancer Group. Myeloablative chemotherapy with autologous bone marrow rescue in children and adolescents with recurrent malignant astrocytoma: outcome compared with conventional chemotherapy: a report from the Children's Oncology Group. Pediatr Blood Cancer. 2008;51(6):806-11.

30. Sanders JE, Growth and development after bone marrow transplantation. In Forman SJ, Blume KG, Thomas ED, editors. Bone Marrow Transplant. Boston, Blackwell Scientific Publications; 1994. pp. 527-537.

31. Sanders JE, Buckner CD, Sullivan KM, et al. Growth and development after bone marrow transplantation. Horm Res. 1988;30(2-3):92-7. 